\title{
Transformation of the Place of Human in Virtual Reality
}

\author{
${ }^{1}$ Liliya M. Salyakhieva, ${ }^{2}$ Zhanna V. Saveleva \\ 1-2 Kazan Federal University \\ Email: gedier@mail.ru
}

Received: 20 ${ }^{\text {th }}$ August 2019, Accepted: $3^{\text {th }}$ September 2019, Published: $31^{\text {st }}$ October 2019

\begin{abstract}
The article presents the approaches and interpretations of virtual reality of various authors, reveals the features of concept interpretation. The features of virtual reality associated with relevance, interactivity, autonomy, immateriality, ephemerality are given. According to J. Baudrillard, the virtual reality simulacra fill the social space, contribute to overproduction of meanings, alienation of human, blurring the boundaries of objective social reality and virtual reality. The article considers the phenomenon of virtual human defined as a new type of personality in social reality, in which socialization, education, work, leisure, interaction, and information flow take place in virtual reality. According to J. Deleuze, it arises the phenomenon of a new "virtual body", which does not reflect any referent in reality, functioning with the help of imagination and fantasies. Virtual reality provides individual freedoms and opportunities, but at the same time creates restrictions for the development of personality, associated, for example, with the Internet addiction. In the article, the authors analyze the data of large research centers regarding the use of the Internet. The results suggest that there are $81 \%$ of Internet users, $62 \%$ of daily users among Russians. The data indicate that the Internet has entered the life of most Russians, who can be called people of the new Homo virtualis formation.
\end{abstract}

Keywords

Social Reality, Virtual Reality, Simulacra, Internet, Virtual Human

\section{Introduction}

The development of modern society leads to the fact that virtual reality arises in addition to the objective reality of existence. Virtuality is considered as a special world, different from the material, really existing one in the broadest sense in science. It is difficult to determine the appearance time of virtuality as a satellite of objective reality. Some scientists believe that it has always been, while others tend to consider it as an attribute of a postmodern society. Virtuality has many different manifestations and can act as an element of the cultural evolution of mankind, as a certain need of the psyche, as a manifestation of increasing computerization and informatization of society. Whatever approach the researcher takes, the study of the virtual human being is of great scientific interest and opens up a huge field for study.

The relevance of the scientific analysis of virtual reality is due to its complexity and ambiguity, many interpretations and approaches of this phenomenon are associated with this. Virtual reality is a self-contained, evolving, rapidly changing structure, which creates additional difficulties for its study. The analysis of virtual reality and its attributes involves an appeal to a whole complex of diverse social processes and meanings that accompany this process. This raises an important research question about changing the role of human and his place in virtuality: from the creator of meanings, images and symbols in the modern world, human becomes a hostage to symbolic reality.

\section{Methods}

In this article, the authors use document analysis methods, including secondary analysis of data from large research centers, in order to verify the theses proposed by the authors.

\section{Results and Discussion}

The modern world is becoming more and more virtualized, replacing the reality of everyday meanings with the reality of simulations. [1] It is especially necessary to note that QMS and the Internet, first of all, act as a space for constructing and transforming meanings, including through the active participation of users in the information process on such virtual sites as chats, forums, social networks, and participation in discussions on news platforms. Under the current conditions, the issue of recognizing and securing to the Internet the status of an instrument for the formation, translation and transformation of certain samples, models, opinions, ideas and stereotypes that have a significant impact on the rethinking of the existing picture of the world of people becomes important.

The concept of virtuality (Lat. virtualis - possible) and virtual reality itself has been used for quite some time. The occurrence of this phenomenon is associated with human attempts to mythologically comprehend the surrounding world, freed from bodily, material existence. Back in the Middle Ages, the concept of virtus was fixed to describe the relationship between the material and non-material worlds. Thus, one can notice that virtuality and ideas about virtual reality have appeared long before the advent of the Internet and computer technology. According to A. Flier, "the main forms of its reconstruction are the manipulation of objects that do not have a place in reality - pseudo-things, simulacra" [2]. According to N.A. Nosov, virtual reality is produced by "generating constant reality". [3] The author believes that it is possible to distinguish several basic properties that virtual reality has, including: relevance (only as long as the constant reality that generates virtual reality is active, we can talk about the existence of the second one); generation (virtual reality 
is initiated by the creating, active, initial reality, which is always external, in relation to it); interactivity (a special property of virtual reality is its ability to interact with other realities, including one that has been generative in relation to it, as well as enter into mutual influence with them); autonomy (the ability of virtual reality to exist according to its own laws in its own space-time continuum, outside the usual concepts of the past and future for a person, only "here and now".

D.V. Ivanov defines virtual reality as a product of the replacement of real phenomena and images with their analogues simulations. "We can talk about virtualization in relation to society, because society becomes like virtual reality, that is, it can be described using the same features. In this case virtualization is any substitution of reality for its simulation/image...". [4] D.V. Ivanov distinguishes as follows among the main features of virtual reality: non-material impact (the image produces effects inherent in the material); conditionality of parameters (objects are artificial and mutable); ephemerality (freedom of entry/exit provides the possibility of interruption and resumption of existence).

The total penetration of virtuality into social reality is emphasized by the fact that all elements of human life are virtualized at the present stage. The elements that make up society are substituted with others. Objects change their appearance, their status, their role. At the same time, we would like to especially emphasize the fact that the virtualization of society is not a fundamentally new phenomenon, since humanity has never lived in pure objective, natural reality. As noted above, scientists have long accepted the fact that people have always created other forms of existence, manifested in religious and ideological teachings. The emergence of humanity was the emergence of human culture as a space of a new reality, an artificial environment at the same time. However, the current stage of development of society, development of information and technical technologies, especially rapid development of the Internet space, takes consideration of virtual reality to a new level.

According to the author of the concept of simulacra, J. Baudrillard, virtual reality replaces objective social reality in the current conditions. Simulacrum in the theory of J. Baudrillard is both a false semblance of reality, hiding the absence of the original, disorienting, harmful, and in the same way, an illusion, an imprint of ideological consciousness.

According to the philosopher, the evolution of society can be considered as the unfolding of the process of society's population with false objects. Thus, there is a slow transition from one state of society to another, from "true" reality to a "false" likeness of reality. The biggest misfortune, according to J. Baudrillard, accompanying a change in the state of society, is an increasing human estrangement from society and oneself, as well as the danger of losing one's own identity due to the constant change of positioning space - from virtual to real, from real to virtual. All this leads to human "loss" by introducing the last feature of polymentalism, that is, constant transitions from virtual reality to ordinary and vice versa. At the same time, modern society, which is characterized by growing computerization, is characterized by wedging virtual reality into everyday life.

According to the idea of J. Baudrillard, the era of postmodernism is the era of total simulation, i.e. time when reality acquires independence by signs and images. Simulations are increasingly conquering the world, spreading to almost all spheres of human life today. Modern society is a society filled with various simulacra, some of which live for a long time, but most - only for a short time. The problem of the simulacra existence is seen by J. Baudrillard in the fact that such simulacra absorb objectively existing reality by filling the social space with themselves. As a result, the boundaries between societies are erased, the functions become blurred, and the social structures are obscure and diffuse. In general, we can say that the opposition between reality and signs is erased and everything becomes a simulacrum. The dominant of simulacra means that society is filled with signs without referents, and images that are not based on real incarnations. Under the influence of ongoing changes, simulations replace the real with the signs of the real. Moreover, the sign exists by itself, without reference to reality and material embodiment, which leads only to the creation of signs of the second order. Thus, the system of simulations begins to self-reproduce in society. In the space of simulation, the real time passes into the category of hyperreal, and all the objects turn into anti-representative, irreferential signs in both artistic, axiological, religious, ethical senses. [5]

With the ever-increasing penetration of virtual reality into everyday life, changes in the human role in it occur. According to G. Deleuze, one of the features of virtual existence is the phenomenon of "body without organs", which manifests itself in the fuzziness of forms, instability of states, rapid change of one phenomenon to another, and complex interaction paths between objects. "Body without organs" is a phenomenon that exists outside of real time, reflecting the possible and impossible transformations, events that have occurred or could happen with a virtual body. The time and perception of a person in the present are changing; they are completely different "here and now" for a virtual body - a body without organs lives on imagination, fantasies, according to the terminology of G. Deleuze. At the same time, a person's virtual body is not a direct reflection of himself/herself in alternative reality, since it receives only those features that a page creator wants to share in the social networks or forums, but at the same time lags behind it in the participation of life situations - information about a person on the Internet will always be late from what happened to the person, even if the gap is a split second.

Thus, it appears a virtual human Homo virtualis and a situation where existence in the virtual world seems much more important and significant than actual existence in reality for an individual. According to the involvement of the subject in virtual reality, according to N.O. Khazieva, the following typology can be made: personality as an active subject of social relations; a person who implements the values of virtual reality in spite of everything; a personality neglecting actual reality in favor of the virtual. [6]

Special features of Homo Virtualis are the desire to spend most of their own lives in virtual space, to satisfy the cultural, social, communicative needs, an excessive focus on virtuality, a possession of virtualized consciousness, to act as the 
creator, carrier and consumer of virtual phenomena. The virtual field becomes a field of work, a field of rest, a field of communication and interaction, consumption of information for the virtual human. One of the inherent features of a virtual human is an increasing dependence on the virtual world, which seems to be especially attractive to a person, since it allows implementing those actions that may not be available to a person in real life. A person acquires the appearance of his/her maximum freedom, because his/her activity - social and cognitive - is now limited only by his/her own imagination. However, everything that happens leads to increasing alienation in society. Researchers of the Homo Virtualis phenomenon, among the many reasons for leaving the virtual world, especially note that it is associated with low "energy intensity", i.e. a person no longer needs to go anywhere and do almost nothing in order to be an active participant in social life. The virtual personality of a human is no longer unreal, non-existent, and does not act as a reflection of a person from the real world today. This is largely due to the fact that the virtual human undergoes his/her socialization in the virtual space, which is quite real for him/her. At the same time, while providing maximum human freedom, virtual reality is simultaneously dependent on the Internet and technical means, which is reflected, for example, in the phenomenon of fubbing. Multiple simulation technologies force a person to participate in an endless race for benefits and desires, which are initially unusual for him/her, create a sense of reality, while making him/her a constant spectator of what is happening on a TV, computer or smartphone.

The increasing virtualization of Russian society and the actualization of a new type of personality are indirectly evidenced by the sociological research data. According to VCIOM (Russian Public Opinion Research Center), the share of Internet users is $81 \%$ in Russia for 2018. The most active group are young people aged 18 to 24 years old, who spend more than 4 hours a day on the World Wide Web every day. On average, $41 \%$ of all respondents go online daily.

Most often, the Internet is used by Russians for work or teaching (44\%), for watching films, reading books and other things $(42 \%)$, for correspondence $(37 \%)$, for broadening one's horizons $(36 \%)$, for tracking news $(35 \%)$, for chatting on forums, on social networks $(28 \%)$. [8]

According to We Are Social and Hootsuite in Russia, the Internet penetration into the lives of citizens is $76 \%$, which is slightly lower than VCIOM notes. [9] However, compared with last year, the main indicators have not changed much, while there was an increase of $7 \%$ in America, with the initial mark of $88 \%$ of Internet users of the total population, and the Internet coverage amounted to $95 \%$ of the population. According to the data presented in the report, there are 5.11 billion unique mobile users in the world and the Internet audience amounts to 4.39 billion people. The Agency has noted growth in all respects: from the Internet coverage worldwide to expanding the circle of users of social networking sites, which amounted to 3.48 billion users at the beginning of 2019. Compared with the data at the beginning of last year, this figure increased by 288 million ( $9 \%)$. [10]

In 2018, according to VCIOM, $62 \%$ of Russians use the Internet for various purposes on a daily basis. At the same time, over the past year, respondents noted situations when they specifically turned off the Internet for a certain period of time (45\%), while $49 \%$ of respondents have never turned off access to the global network on purpose at the same time. The survey participants noted that there have been situations in life when they were forced to end up without the Internet for a full day or longer - $66 \%$ of respondents - over the past year. At the same time, $8 \%$ note their negative feelings, depression, anxiety, etc., associated with this fact, and 7\% - positive feelings, joy, relaxation, etc. The majority of respondents - $83 \%$ - say that they have not felt any significant changes. 39\% of the VCIOM survey participants indicated that the disappearance of the Internet will significantly change their lives, but they will be able to adapt. [11]

\section{Summary}

Modern society is characterized by a rapid change of processes that supersede each other. Virtualization is only one of the phenomena of the modern world, which is of great interest for the scientific study. From various points of view, virtuality represents a wide range of possibilities for the scientific study as an attribute of the human psyche, the technical and technological manifestation of progress or the evolution of social communication. The technical and technological aspects of virtualization associated with the development of computer technology, global networks and digitalization are of particular importance in the current conditions.

The above data from mass surveys and monitoring indicate that the Internet has become quite solid in the lives of most Russians, who can be called people of the new Homo Virtualis formation. Modern human is increasingly making attempts to get away from objective reality into virtual one for self-expression, self-realization, freedom, but at the same time he/she falls into new types of addictions.

\section{Conclusions}

The emergence of such a phenomenon as a virtual human suggests that virtual reality becomes independent and selfsufficient. In the social space, the connection between the referent and the sign is broken, the virtual world becomes an objective social reality for a new type of person. The place of the individual in symbolic reality is gradually changing. If it was possible to talk about the creative, creating the beginning of human in the virtual space at first, now we can notice the individual shifting to the position of the dependent element of the new system, when the lack of access to the symbolic reality of new media creates serious discomfort for the user. 


\section{Acknowledgements}

The work is performed according to the Russian Government Program of Competitive Growth of Kazan Federal University.

\section{References}

[1] J.Baudrillard, "Simulacra and Simulations. The Precession of Simulacra", European Graduate School. URL: http:/www.egs.edu/faculty/jean-baudrillard/articles/simulacra-and-simulations-i-the-precession-of-simulacra (01.05.2019)

[2] Flier A.Ya. Culture as a Virtual Reality, Bulletin of the Moscow State University of Culture and Arts. 2006. V. 4. P. 12-16.

[3] Nosov N. A. Virtual Psychology. M., 2000. P. 27.

[4] Ivanov D. B. Virtualization of Society. SPb., 2000. P. 30.

[5] J. Macgregor (1997) Wise Exploring Technology and Social Space. NewYork.

[6] G. Deleuze (1990) Logic of sense. London. P.188-189.

[7] N. Khazieva, A. Khaziev, \& E.Klyushina (2018) "Digital Society: The Experience of the Philosophical Understanding of a Problem", Journal of History Culture and Art Research, vol. 7(4), pp. 347-353.

[8] The Internet: for Work or Entertainment? // Press release of VCIOM No. 3767. September 20, 2018. URL: https://wciom.ru/index.php?id=236\&uid=9322 (01.05.2019)

[9] Digital in 2019 / We are social. URL: https://wearesocial.com/global-digital-report-2019 (01.05.2019)

[10] Digital 2019: The Russian Federation / DataReportal. URL: https://datareportal.com/reports/digital-2019-russianfederation (01.05.2019)

[11] Life on the Internet and Without It // Press release of VCIOM No. 3624. April 4, 2018. URL: https://wciom.ru/index.php?id=236\&uid=9024 (01.05.2019) 